\title{
Effects of melatonin on the ovarian response to pinealectomy or continuous light in female rats: similarity with polycystic ovary syndrome
}

M.F. Prata Lima ${ }^{1}$,

E.C. Baracat ${ }^{2}$ and M.J. Simões ${ }^{3}$

\author{
1Disciplina de Ginecologia e Obstetrícia, \\ Faculdade de Medicina do Triângulo Mineiro, Uberaba, MG, Brasil \\ Departamentos de ${ }^{2}$ Ginecologia and ${ }^{3}$ Histologia, Escola Paulista de Medicina, \\ Universidade Federal de São Paulo, São Paulo, SP, Brasil
}

\section{Correspondence \\ M.F. Prata Lima \\ Rua São Sebastião, 357 \\ 38010-430 Uberaba, MG \\ Brasil \\ E-mail:marco_fabio@uol.com.br}

Publication supported by FAPESP.

Received December 17, 2002

Accepted March 4, 2004

\section{Abstract}

The current study was conducted to investigate the relationship between melatonin and chronic anovulation. Adult (3-4 months old) female Wistar rats were submitted to pinealectomy: group I: pinealectomized ovariectomized melatonin-treated $(\mathrm{N}=10)$; group II: pinealectomized ovariectomized placebo-treated $(\mathrm{N}=12)$; group III: pinealectomized light-treated placebo-treated $(\mathrm{N}=10)$ or maintained under continuous light; group IV: maintained under continuous light, ovariectomized melatonin-treated $(\mathrm{N}=22)$; group $\mathrm{V}$ : maintained under continuous light, ovariectomized placebo-treated $(\mathrm{N}=10)$; group VI: maintained under continuous light placebo-treated $(\mathrm{N}=10)$. In order to assess ovarian modifications, unilateral ovariectomy was performed during the fourth month in groups I, II, IV, V and the other ovary was removed after 8 months. Ovariectomy was performed in groups III and VI only after eight months. Melatonin (200 $\mu \mathrm{g} / 100 \mathrm{~g}$ body weight) dissolved in $0.02 \mathrm{ml}$ absolute ethanol was injected intramuscularly daily during the last 4 months into groups I and IV. The other groups were treated with placebo $(\mathrm{NaCl})$. The ovarian cysts were analyzed and their area, perimeter and maximum diameter, as well as the thickness of the ovarian capsule were measured. Daily colpocytological smears were performed throughout the study. Persistent estrous condition and ovarian cysts were observed in all groups. In pinealectomized rats the ovarian and vaginal alterations disappeared at the end of the study and in rats maintained under continuous light the vaginal and ovarian polycystic aspect was reversed only in those treated with melatonin. We conclude that melatonin may act on the ovarian response reverting chronic anovulation induced by pinealectomy or continuous light.
Key words - Melatonin

- Polycystic ovary syndrome

- Pineal body

- Anovulation 


\section{Introduction}

The participation of the pineal gland in the regulation of seasonal, photoperiodicdependent reproduction has been firmly established but is poorly understood. Melatonin is the principal hormone produced by the pineal gland (1-4). Its release is mainly due to pineal secretion but $25 \%$ of melatonin production is of extra-pineal origin $(5,6)$. Melatonin secretion is generated by norepinephrine (NEP) pulses, which is released from neighboring neurons. This NEP-releasing activity and the functioning of the pineal are activated in darkness and inhibited by light. The dark-light conditions are transmitted through the eyes to the suprachiasmatic nucleus ( $\mathrm{SCN})$, whose signals are inhibited in light and activated by the absence of this inhibition in the dark (7).

The mechanisms by which melatonin acts on the neuroendocrine systems to affect reproduction are not known. One plausible possibility is that melatonin acts directly by affecting the hypothalamic functions involved in the inhibitory regulation of gonadotrophin-releasing hormone (GnRH) $(6,7)$. The release of pituitary gonadotrophic hormones, follicle-stimulating hormone (FSH) and luteinizing hormone (LH), often occurs on a rhythmic basis with the period of release ranging from an ultradian (i.e., about 1$4 \mathrm{~h}$ ) to a circadian (i.e., about $24 \mathrm{~h}$ ) and a seasonal (i.e., about 1 year) pattern. In photoperiodic species, the pattern of melatonin secretion from the pineal gland mediates the effects of day length on the seasonal reproductive cycle (8). In these species, melatonin has a pro-gonadotrophic effect, increasing FSH concentrations and LH pulses, probably by inhibiting the inhibitory effects of sexual steroids on ovulation (9-11). In a number of rodent species and other mammals, the preovulatory release of gonadotrophins is tightly controlled by a neural circadian clock. These are called non-photoperiodic species, most of them with short-term periods of pregnancy, which do not obey a seasonal reproductive rhythm, but present a daily circadian rhythm of melatonin release. Thus, in rodents, melatonin has marked antigonadotrophic properties, such as inhibition of gonadal development, spermatogenesis and androgen production in males and absence of follicles, corpora lutea and interstitial tissue proliferation in female rats $(9,12)$.

The gonadal axis of the laboratory rat can respond to pinealectomy, to exogenous melatonin administration or to the presence or absence of light. Well-known manipulations are neonatal androgenization, chronic testosterone administration to intact rats, olfactory bulbectomy, and fasting. All of these manipulations can be reversed by pinealectomy $(13,14)$.

Few studies have evaluated the possible relations between the variations in melatonin levels and the development of morphophysiologic ovarian alterations. Thus, the reports of the effects of different doses of melatonin given to rats submitted to constant light or pinealectomy are contradictory, varying according to the intensity of light or to the methodologies employed. In the adult female rat, injection of large doses of melatonin in the afternoon of proestrus can inhibit the preovulatory LH and can block the expected ovulation (12). In addition, early puberty, ovarian atrophy, chronic non-ovulation, permanent estrous condition, and hyperprolactinemia have been described in rodents submitted to both pinealectomy and continuous light regimens (15). Some studies have shown that under constant light or after pinealectomy, the vagina of female rats cornifies, with the animals experiencing constant estrus and failing to ovulate $(8,16,17)$.

The aim of the present study was to determine the effect of the chronic absence of melatonin on morphology of rat ovaries, as well as to identify the effects of exogenous melatonin administration to pinealectomized rats and to rats maintained under continuous light. 


\section{Material and Methods}

Female Wistar rats (Rattus norvegicus albinus) were obtained from the colony of Escola Paulista de Medicina, São Paulo, SP, Brazil (EPM-1 Wistar). The animals were housed in individual clear plastic cages and standard rat chow and tap water were available ad libitum. Artificial illumination was provided by cool white fluorescent lamps that supplied a luminous intensity of $500 \mathrm{lux}$ at the level of the cages. The rats were young adults (3-4 months) and weighed $350 \pm 33 \mathrm{~g}$ (pinealectomy, $\mathrm{N}=61$ ) and $337 \pm 36 \mathrm{~g}$ (continuous light, $\mathrm{N}=52$ ) at the beginning of the study.

After an adaptation period of seven days, vaginal smears were obtained from the rats to determine their cyclicity over a 30-day period. The rats showed repetitive estrous cycles and vaginal smears continued to be obtained throughout the experiment.

One aim of the present study was to confirm the report of the development of ovarian cysts 90 days after pinealectomy (18) and to extend it by determining if the same occurs in rats kept under continuous light. Thus, the animals were divided into two major categories as follows:

Pinealectomized groups: 61 rats divided into three groups

Group I $(N=22)$ - Pinealectomized ovariectomized melatonin-treated group. Pinealectomized rats were housed under 12-h light:dark cycles (lights on at 8:00 h) at a temperature of $23^{\circ} \mathrm{C}$. The right ovaries were studied after ovariectomy after 4 months. During the subsequent 4 months, the animals were treated with melatonin. At the end of 8 months, the left ovaries were removed and studied.

Group II $(N=24)$ - Pinealectomized ovariectomized placebo-treated group. Pinealectomized rats were submitted to the same protocol as the pinealectomized mela- tonin-treated group, although after right ovariectomy the rats were treated with placebo for 4 months. Similarly, the left ovaries were analyzed at the end of the study.

Group III $(N=15)$ - Pinealectomized light-treated placebo-treated group. Pinealectomized rats were exposed to continuous light for 8 consecutive months. At the end of the experiment, left ovariectomy was performed. The rats were treated with placebo during the last 4 months.

Three pinealectomized ovariectomized melatonin-treated rats and 4 pinealectomized ovariectomized placebo-treated rats died after pinealectomy, and massive intracranial bleeding was observed in all of them. Seven rats from groups I and II and 5 rats from group III did not show vaginal cyclicity and were excluded from the experiment. Two pinealectomized ovariectomized melatonintreated rats and 1 pinealectomized ovariectomized placebo-treated rat died after right ovariectomy.

\section{Continuous light groups: $\mathbf{5 2}$ rats divided into three groups}

Group IV $(N=26)$ - Continuous-light ovariectomized melatonin-treated group. Rats were exposed to continuous light for 8 months. Right ovariectomy was performed after the first 4 months and melatonin was administered during the subsequent 4 months. At the end of the experiment, left ovariectomy was also carried out.

Group V $(N=13)$ - Continuous light ovariectomized placebo-treated group. Rats were submitted to the same protocol as the previous group, although placebo was administered for the 4 subsequent months instead of melatonin. At the end of the experiment, left ovariectomy was performed.

Group VI $(N=13)$ - Continuous light placebo-treated group. Rats were exposed to continuous light for 8 consecutive months. At the end of the experiment, left ovariectomy was performed. The rats were treated 
with placebo during the last 4 months.

Only the animals that survived until the end of the experiment were studied, i.e., 22 animals from the continuous light melatonin-treated group and 10 from the continuous light placebo-treated and 10 from the continuous light ovariectomized placebotreated groups, respectively.

\section{Pinealectomy}

The animals were anesthetized intraperitoneally with $15 \mathrm{mg} / \mathrm{kg}$ xylazine (Rompun ${ }^{\circledR}$ ) in combination with $30 \mathrm{mg} / \mathrm{kg}$ ketamine $\left(\operatorname{Ketalar}^{\circledR}\right)$. The animal was fastened to the dissection table, an incision was made in the skin and the subcutaneous tissue, bringing the lambda into view. The skullcap was opened with the aid of a micromotor, bringing the cerebral hemispheres and the superior sagittal sinus into view. The pineal gland, located under the venous sinus, was removed in one piece using tweezers. Next, the bone fragment was returned to its place and the surgical layers were sutured. After surgery, the animals received a single dose of prophylactic antibiotic.

\section{Ovariectomy}

The animals were anesthetized with 15 $\mathrm{mg} / \mathrm{kg}$ xylazine (Rompun ${ }^{\circledR}$ ) in combination with $30 \mathrm{mg} / \mathrm{kg}$ ketamine $\left(\operatorname{Ketalar}^{\circledR}\right)$. The abdominal wall was opened and the ovaries were identified and resected. The ovaries were then processed, cut and stained with hematoxylin-eosin.

\section{Melatonin and placebo treatment}

Doses of $200 \mu \mathrm{g}$ melatonin per $100 \mathrm{~g}$ body weight were used. Melatonin, purchased from Sigma, St. Louis, MO, USA, was dissolved in a small volume of absolute ethanol $(0.02 \mathrm{ml})$ and diluted in $0.9 \% \mathrm{NaCl}$ to a dose of $200 \mu \mathrm{g}$ per $100 \mathrm{~g}$ body weight. Melatonin injections were performed intramuscularly between 18:00 and 19:00 h. Control animals received a placebo solution $(\mathrm{NaCl})$.

\section{Histomorphometry}

Histomorphometric analysis was performed directly on the slide using the MOPplan system. The cyst profile was delineated and the area, perimeter and maximum diameter of the cysts and the thickness of the ovarian capsule were calculated.

\section{Colpocytological examination}

Vaginal smears were obtained throughout the study using cotton swabs dampened in saline solution. The smears were transferred to histological slides and stained by the Shorr-Harris method. The four phases of the estrous cycle of the rat (estrus, pro-estrus, meta-estrus and diestrus) were identified.

\section{Statistical analysis}

Data were analyzed statistically by the Wilcoxon and Mann-Whitney nonparametric tests, with the level of significance set at $\mathrm{P}<0.05$ (19).

\section{Results}

\section{Pinealectomized groups}

Ninety percent of the rats developed continuous estrus after 60 days in the three pinealectomized groups (groups I, II and III), with spontaneous reversal by day 100 . The ovarian weights did not change in these three pinealectomized groups. Fifty-five percent of the ovaries studied presented interstitial tissue proliferation in groups I and II at 4 months and in group III at 8 months.

In pinealectomized ovariectomized rats (groups I and II), the ovaries developed a polycystic aspect at 4 months, but the cysts reduced spontaneously at the end of the study 
(8 months) despite melatonin or placebo administration. The number of ovarian cysts fell significantly $(\mathrm{P}<0.05)$ from $5.5 \pm 1.5$ to $2.1 \pm 1.2$ in group I and from $4.4 \pm 1.7$ to 2.8 \pm 1.4 in group II (Figures 1 and 2). Analysis of ovarian histomorphometry (area, perimeter, and diameter of cysts and thickness of ovarian capsule) did not show significant differences at the times studied (Figures 3 and 4). There were no statistical differences between groups II and III (pinealectomized ovariectomized placebo-treated $v s$ pinealectomized light-treated placebo group) in the number of ovarian cysts nor on their histomorphometry at 4 and at 8 months.

\section{Constant light group}

One hundred percent of the rats developed permanent estrus after 90 days of light exposure. Permanent estrous condition disappeared only in the group treated with melatonin (group IV) by day 140. In the groups kept under continuous light placebo-treated (groups V and VI) permanent estrus was present throughout the study. The weight of the ovaries showed a statistically significant reduction $(\mathrm{P}<0.05)$ at 8 months only in the group treated with melatonin (group IV). Eighty-five percent of the ovaries in groups $\mathrm{IV}$ and $\mathrm{V}$ at 4 months and in group VI at 8 months showed interstitial tissue proliferation.

All animals of the ovariectomized groups maintained under continuous light (groups IV and V) showed polycystic ovaries aspect at 4 months. The number of ovarian cysts fell significantly $(\mathrm{P}<0.05)$ from $8 \pm 2.2$ to $3.0 \pm$ 1.5 in group IV. This phenomenon did not occur in the continuous light ovariectomized placebo-treated group (group V, Figure 1).

As shown in Figure 3 the areas and maximum diameters of the cysts in the continuous light ovariectomized melatonin-treated group (group IV) were significantly larger ( $\mathrm{P}$ $<0.05)$ at 4 months when compared to those values observed at 8 months. These morpho- metrical alterations of the ovarian cysts were not observed in the placebo-treated group (group V, Figure 3). Comparative analysis of ovarian capsule thickness did not demonstrate significant differences between groups IV and $\mathrm{V}$ at 4 and 8 months (Figure 3 ). There were no statistical differences between groups

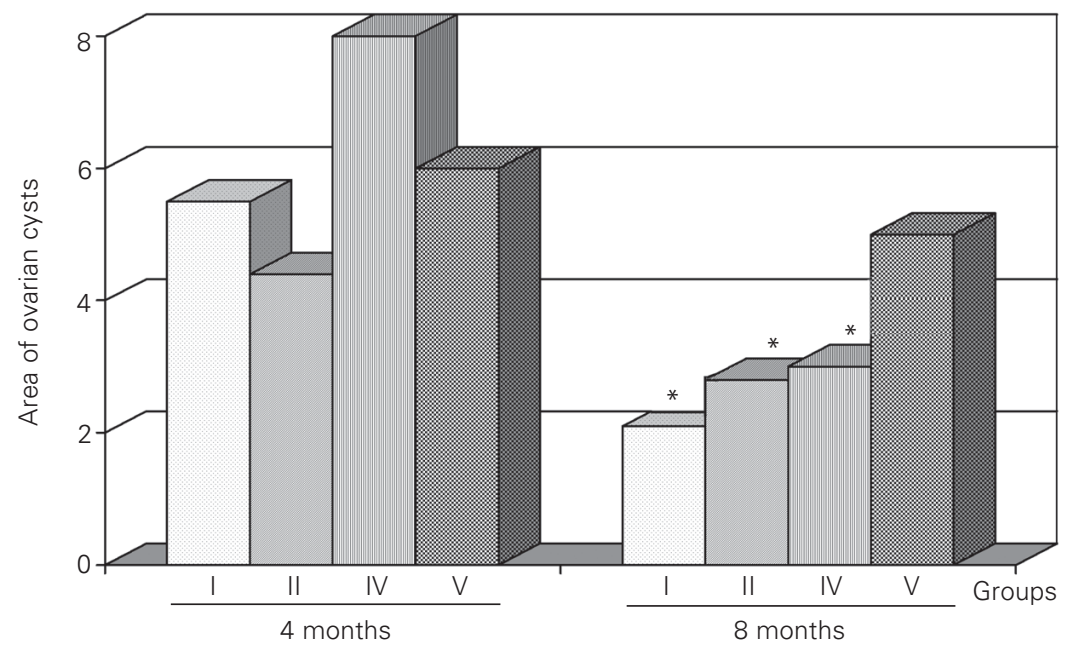

Figure 1. Number of cysts in the right ovary at 4 months and in the left ovary at 8 months before and after melatonin or placebo administration. Group I: pinealectomized ovariectomized melatonin-treated group; group II: pinealectomized ovariectomized placebo-treated group; group IV: continuous light ovariectomized melatonin-treated group; group V: continuous light ovariectomized placebo-treated group. ${ }^{*} P<0.05$ compared to 4 months (Wilcoxon nonparametric test).
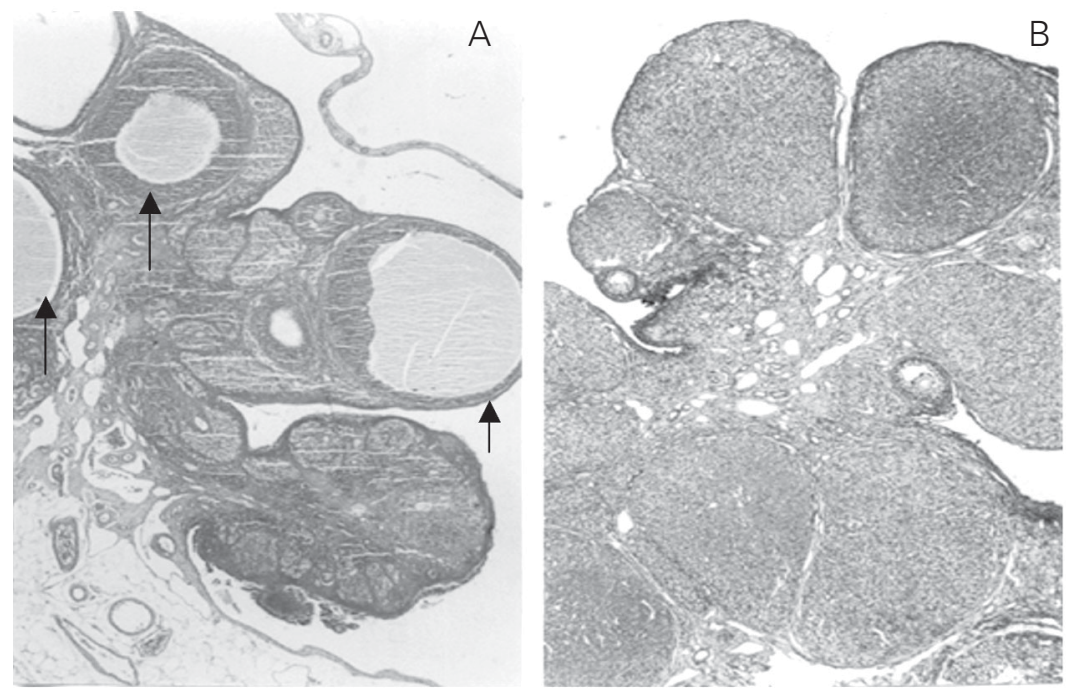

Figure 2. Morphological aspects of the ovaries of the rats from group I (pinealectomized ovariectomized melatonin-treated group), before (A) and after (B) melatonin administration. The induction and regression of ovarian polycystosis (arrows) is indicated by a significant reduction of the ovarian cysts after melatonin treatment. Hematoxylin and eosin $( \pm 180 \mathrm{X})$. 
$\mathrm{V}$ and VI (continuous light ovariectomized placebo-treated $v s$ continuous light placebotreated group) in the number of ovarian cysts nor on their histomorphometry.

\section{Discussion}

The present study describes the development of ovarian cysts in rats similarly to that observed in human polycystic ovary syndrome (PCOS) and their regression under
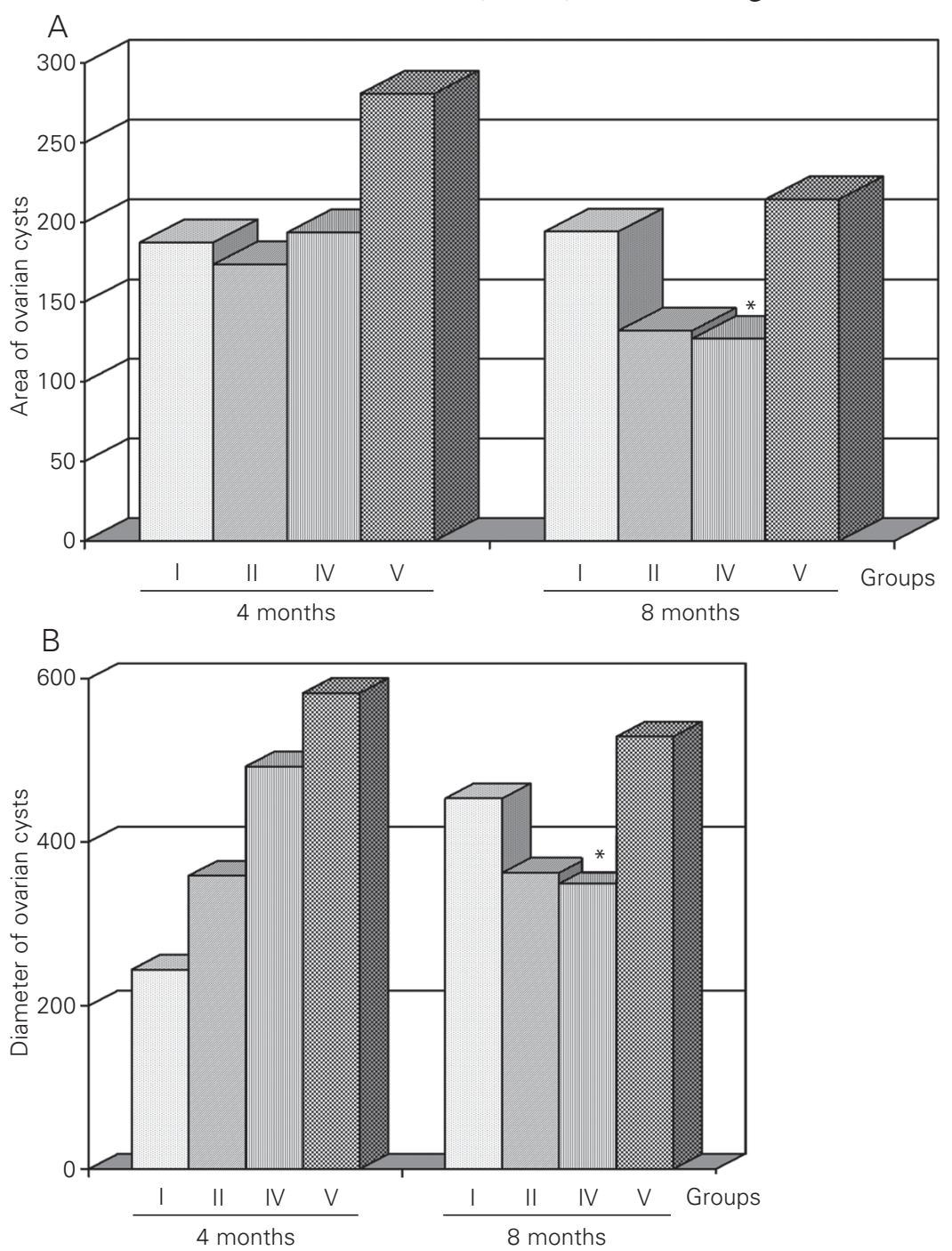

Figure 3. Area (A) and diameters (B) of the ovarian cysts in the right ovary at 4 months and in the left ovary at 8 months before and after melatonin or placebo administration. Group I: pinealectomized ovariectomized melatonin-treated group; group II: pinealectomized ovariectomized placebo-treated group; group IV: continuous light ovariectomized melatonintreated group; group V: continuous light ovariectomized placebo-treated group. ${ }^{*} P<0.05$ compared to 4 months (Wilcoxon nonparametric test). two different experimental conditions, both of them hypothetically extinguishing the production of melatonin. PCOS is a common disorder characterized by chronic anovulation and bilateral polycystic ovaries, without truly unique clinical parameters. Although much research has been carried out in this area, the physiopathology of PCOS remains unexplained and there is no single laboratory test that provides a diagnosis (20-22).

It is believed that the development of polycystic ovaries is a response to some form of chronic anovulation, with hyperandrogynism being crucial for the development of the syndrome (23). Mild hyperinsulinemia and insulin resistance are common findings in PCOS and influence the clinical presentation of the disorder (24) but these findings do not explain its whole spectrum. Alteration of central nervous system structures in the pathogenesis of PCOS is one of the most tested hypotheses but its relation to physiopathology is still unknown $(18,20)$.

Although there has been a lack of a satisfactory animal model for the disease, the occurrence of ovarian cysts in many mammals has led to the use of rodents to examine the neurological mechanisms involved in the onset of PCOS (21). Thus, we decided to test two well-known experimental situations, i.e., pinealectomy and continuous light.

The results of the present study show that a transitory estrous condition similar to human vaginal cornification, usually observed in PCOS, occurred in rats submitted to pinealectomy. In pinealectomized rats, the continuous estrous condition developed and it could be reversed. A significant reduction in the number of cysts observed in the pinealectomized ovariectomized melatonin-treated (group I) was probably a result of the antigonadotrophic effects of melatonin (14). Pinealectomy probably produced gonadotrophic alterations, leading to ovarian cyst development. The absence of melatonin may have modified gonadotrophin secretion, in- 
creasing the synthesis of $\mathrm{LH}$ and reducing the synthesis of FSH. The LH increase may have been responsible for the interstitial tissue proliferation observed in some of the animals, whereas the increase in LH secretion is a major condition observed in PCOS $(20,21)$. The reduction in ovarian cysts in the placebo group may be explained as a partial compensation by extra-pineal melatonin-producing cells due to the fact that plasma melatonin levels are reduced by pinealectomy $(5,6)$. Dardes et al. (25) observed that in pinealectomized rats there is a reduction, but not the disappearance, of urinary 6-sulfatoxymelatonin excretion, indicating that there is synthesis of melatonin at sites other than the pineal gland. The lack of reduction in ovarian cortex thickness suggests that there was insufficient time for this event to be manifested, or that enlargement of the ovarian cortex did not occur. The development of ovarian cysts and chronic anovulation presented above indicate a behavior also seen in patients with PCOS $(21,23)$. Other supporting findings indicate that circulating estrogens increase in pinealectomized rats. Teixeira (26) observed that the endometrium of rats submitted to pinealectomy presented hyperplasia, which was reversed with the use of melatonin. Endometrium hyperplasia and increase of circulating estrogens are also frequently reported in PCOS $(20,24)$.

Melatonin also acts on the central nervous system of rodents, with an anti-gonadotrophic action on the anterior hypothalamus (1-3). In male hamsters, exposure to long periods of darkness leads to a drop of gonadotropin levels and consequently to gonad atrophy and these effects are blocked by pinealectomy, but in this situation the animals do not reproduce (27).

The results observed in pinealectomized groups (I, II and III) indicate that an abnormal endocrine environment was generated in the SCN and in the ovarian of rats. Buijs et al. (28) recently suggested that the SCN uses different types of neuronal targets to pass on its circadian signal: direct communication with neuroendocrine neurons, with autonomic neurons in the paraventricular nucleus (PVN) of the hypothalamus, with hypothalamic structures between the SCN and the anterior PVN of the thalamus (PVT), and communication with areas outside the hypothalamus. The melatonin rhythm appears to
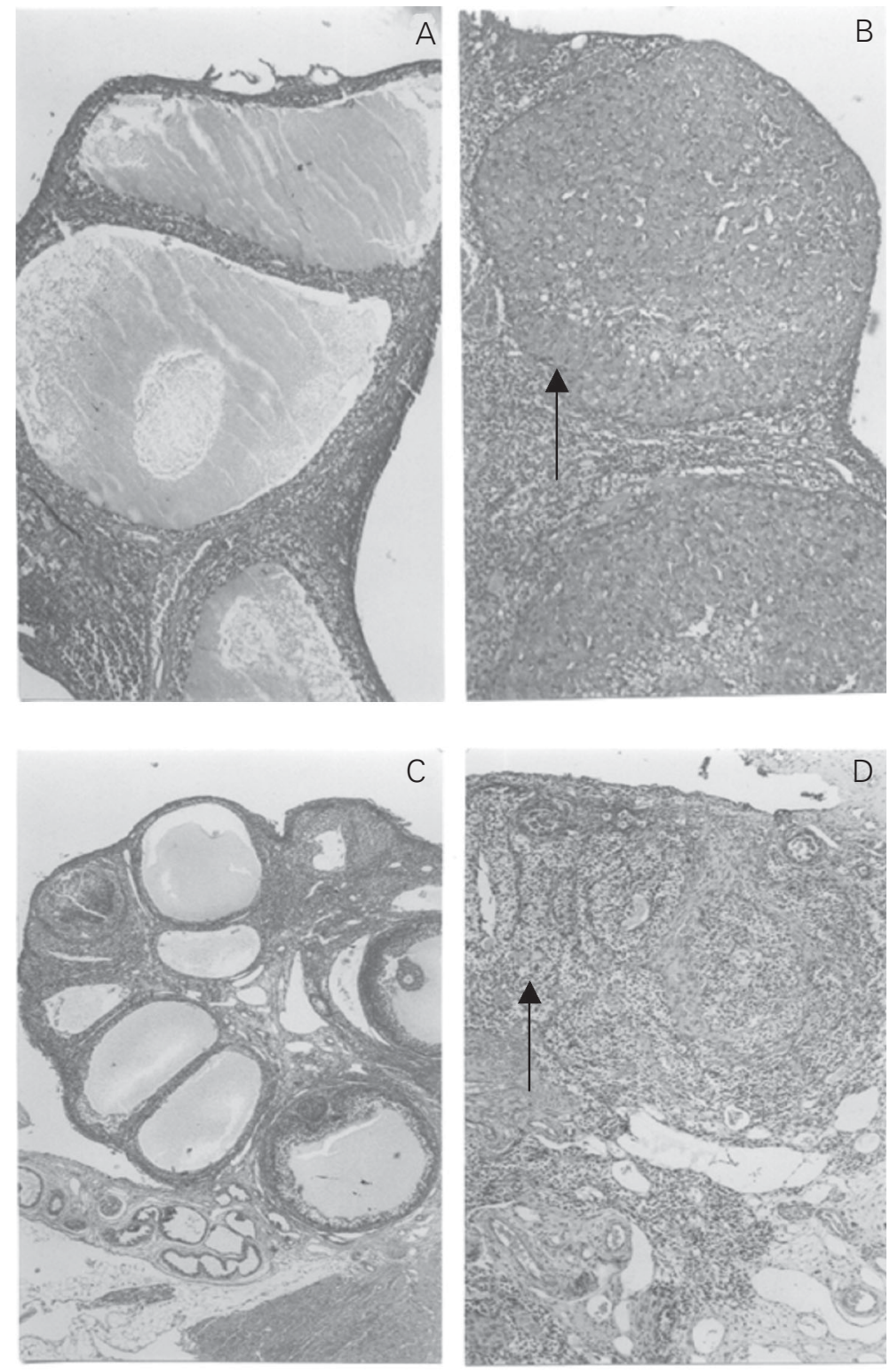

Figure 4. Ovaries from group IV rats (continuous light ovariectomized melatonintreated group). The induction and regression of polycystic ovaries before $(A, C)$ and after $(B, D)$ melatonin replacement is indicated by an important reduction of ovarian cysts and by the presence of corpora lutea (B) and by interstitial tissue proliferation (D) as indicated by arrows. Hematoxylin and eosin ( $\pm 180 \mathrm{X})$. 
be an endocrine code of the environmental light-dark cycle conveying photic information that is used by an organism for both circadian and seasonal temporal organization (29-31) and it seems that there is no regular fluctuation in the pineal metabolism leading to melatonin synthesis and release throughout the estrous cycle in female rats (32,33).

The SCN is also fundamental in the induction of renewed positive estrogen control of the preovulatory wave of $\mathrm{LH}$, and melatonin may act together with the hypothalamus in altering the secretion of GnRH and the consequent production of gonadotropins (16). As a result, melatonin reduces the release of LH and FSH (34-36). This may interfere with the pulsatile ability of $\mathrm{GnRH}$, acting directly on the control of the synthesis of gonadotropins or dopamine, or acting indirectly on the PVN and the PVT $(37,38)$.

The rats of the groups IV, V and VI, maintained under continuous light, developed persistent estrus that was reversed only in the group treated with melatonin. Analysis of the ovaries showed a significant reduction in the number of cysts in the animals that received melatonin, but not in the animals that received placebo. This suggests that light inhibits melatonin-producing cells located at the pineal gland level. Additionally, analysis of cyst area, perimeter and diameter showed a reduction only in the melatonintreated group.

The alterations observed in pinealectomy and continuous light presented here suggest that the reductions in melatonin levels in rats may lead to the development of PCOS. Some evidence appears to support this hypothesis. In the absence of melatonin there is an increase in the activity of cytochrome P450$\mathrm{C} 17$, which acts on steroid pathways by promoting an increase in $17 \mathrm{OH}$-progesterone levels and hence in androgen levels. This alteration is also commonly observed in PCOS (39). On the other hand, melatonin appears to increase peripheral insulin sensitivity, especially in adipocytes (40). Thus, it is obvious to suppose that in PCOS the absence of melatonin may increase insulin peripheral resistance, but data of this interpretation need to be presented.

In summary, the data reported here show a strong relationship between melatonin, and probably the pineal gland, and the rodent equivalent of PCOS. This provides a very promising model for the study of this syndrome which may be extrapolated to clinical situations.

\section{References}

1. Moore RY (1990). Mecanismos neuroendócrinos - células e sistemas. In: Yen SSCC \& Jaffe RB (Editors), Endocrinologia Reprodutiva. Editora Roca, São Paulo, SP, Brazil, 19-20.

2. Reichlin S (1992). The pineal gland. In: Wilson JD \& Foster D (Editors), Williams Textbook of Endocrinology. 8th edn. Saunders WB, Philadelphia, PA, USA, 240-253.

3. Klein DC (1978). The pineal gland: a model of neuroendrocrine regulation. In: Reichlin S, Baldessarini RJ \& Martin JB (Editors), The Hypothalamus. Raven Press, New York, 303-327.

4. Lewy AJ (1983). Biochemistry and regulation of mammalian melatonin production. In: Relckin R (Editor), The Pineal Gland. Elsevier Biomedical, New York, 77-128.

5. Cardinali DP \& Rosner JM (1971). Retinal localization of HIOMT in the rat. Endocrinology, 89: 301-307.

6. Djeridane $Y$, Vivien-Roels B, Simonneaux V, Miguel JM \& Pevet $P$ (1998). Evidence for melatonin in rodent Harderian gland: a dynamic in vitro study. Journal of Pineal Research, 25: 54-64.
7. Arendt $J$ (1995). The pineal gland: basic physiology and clinical implication. Endocrinology, 1: 432-444.

8. Tamarkin L, Baird CJ \& Almeida OFX (1985). Melatonin: a coordinating signal for mammalian reproduction. Science, 227: 714-720.

9. Karsch FJ, Bittman L, Foster DL, Goodman RL, Legan SJ \& Robinson JE (1984). Neuroendocrine basis of seasonal reproduction. Recent Progress in Hormone Research, 40: 185-227.

10. Lincoln GA (1992). Photoperiod-pineal-hypothalamic relay in sheep. Animal Reproduction Science, 28: 203-217.

11. Tortonese DJ \& Lincoln GA (1995). Effects of melatonin the mediobasal hypothalamus on the secretion of gonadotropin in sheep: role of dopaminergic pathways. Journal of Endocrinology, 146: 543-552.

12. Turek FW, Losee-Olson S, Swann JM, Horwath K, Van Cauter E \& Milette EV (1987). Circadian and seasonal control of neuroendocrine-gonadal activity. Journal of Steroid Biochemistry, 24: 573-579.

13. Freeman ME (1994). The neuroendocrine control of the ovarian 
cycle of the rat. In: Knobil E \& Neill JD (Editors), The Physiology of Reproduction. 2nd edn. Raven Press Ltd., New York, 613-652.

14. Glass JD (1988). Neuroendocrine regulation of seasonal reproduction by the pineal gland and melatonin. Pineal Research Reviews, 6: 219-259.

15. Acuña-Castroviejo D, Fernandez B, Castilho JL \& del Aguila CM (1993). Similarity between the effects of suprachiasmatic nuclei lesions and of pinealectomy on gonadotropin release in ovariectomized, sulpiride-treated and melatonin-replaced rats. Experientia, 49: 497-801.

16. Chan WY \& Ng TB (1995). Effects of pineal indoles on ovarian response to gonadotropin-induced ovulation in mice. Journal of Neural Transmission, 100: 239-246.

17. Guisado E, López MD, Pinilla L, Collado MD \& Aguilar E (1983). Efecto de la iluminación constante sobre la respuesta a la castración en ratas. Revista Española de Fisiologia, 39: 231-236.

18. Prata Lima MF, Reis MA, Soares JM, Salum R \& Baracat EC (1995). Development of ovarian polycystosis after pinealectomy in female rats. Reprodução e Climatério, 10: 73-75.

19. Siegel S \& Castellar Jr NJ (1988). Non-parametric Statistics. 2nd edn. McGraw-Hiclint, New York, 399-405.

20. Lobo RA \& Carmina E (1997). Polycystic ovary syndrome. In: Lobo RA, Mishell DR, Paulson RJ \& Shoupe D (Editors), Infertility, Contraception and Reproductive Endocrinology. Blackwell Science, Malden, MA, USA, 364-383.

21. Polson D, Wadswordth J, Adams J \& Francks S (1988). Polycystic ovaries: a common finding in normal women. Lancet, 1: 870-872.

22. Adams J, Polson DW \& Franks S (1986). Prevalence of polycystic ovaries in women with anovulation and idiopathic hirsutism. British Medical Journal, 293: 355-359.

23. Poretsky LL \& Piper V (1994). Insulin resistance, hypersecretion of $\mathrm{LH}$ and dual effect hypothesis for the pathogenesis of polycystic ovary syndrome. Obstetrics and Gynecology, 84: 623-627.

24. Barbieri RL, Makris A, Randall RW, Daniels G, Kistner RW \& Ryan $\mathrm{KL}$ (1986). Insulin stimulates androgen accumulation in circulation of ovary stroma from women with hyperandrogenism. Journal of Clinical Endocrinology and Metabolism, 62: 904-910.

25. Dardes RC, Baracat EC \& Simões MJ (2000). Modulation of estrous cycle and LH, FSH and melatonin levels in pinealectomy and shampinealectomy in female rats. Progress in Neuro-Psycopharmacology and Biological Psychiatry, 24: 441-453.

26. Teixeira AAC (1998). Aspectos morfológicos do endométrio, na fase de estro, de ratas pinealectomizadas, São Paulo. Master's thesis, Escola Paulista de Medicina, Universidade Federal de São Paulo, São Paulo, SP, Brazil, 185-227.

27. Groose J, Maywood ES, Ebling FJP \& Hastings MH (1993). Testicular regression in pinealectomised Syrian hamsters following infusion of melatonin delivered in non-circadian schedules. Biology of Reproduction, 49: 666-674.
28. Buijs RM, van Eden CG, Goncharuk VD \& Kalsbeek A (2003). The biological clock tunes the organs of the body: timing by hormones and autonomic nervous system. Journal of Endocrinology, 177: 1726.

29. Yamasaki S, Mumano R, Abe M, Hida A, Takahashi R, Ueda M, Block GD, Sakaki Y, Menaker M \& Tei H (2000). Resetting central and peripheral circadian oscillators in transgenic rats. Science, 288: 682-685.

30. Pevet P (1998). Melatonin and biological rhythms. Therapie, 53: 411-420.

31. Skouupa AL, Garidou ML, Bothorel B, Saboureau M, Pevet P, Neto JC \& Simonneaux V (2003). Pineal melatonin synthesis and release are not altered throughout the estrous cycle in female rats. Journal of Pineal Research, 34: 53-59.

32. Saboureau M, Masson-Pevet M, Cauguilhem B \& Pevet $P$ (1999). Circannual reproductive rhythm in European hamster: demonstration of the existence of an annual phase of sensitivity to short photoperiod. Journal of Pineal Research, 26: 9-16.

33. Buijs RM, Wortel J \& Hou YX (1995). Co-localization of gammaaminobutyric acid with vasopressin, vasoactive intestinal peptide and somatostatin in the rat suprachiasmatic nucleus. Journal of Comparative Neurology, 358: 343-352.

34. Ozaki Y, Wurtman R, Alonso R \& Lynch HJ (1978). Melatonin secretion decreases during the proestrous stage in the rat estrous cycle. Proceedings of the National Academy of Sciences, USA, 75: 531-534.

35. Gay VL \& Tomacarini RL (1974). Follicle stimulating hormone in the female rat: cyclic release is dependent on circulating androgen. Science, 184: 75-77.

36. Gay VL, Midgley AR \& Niswender GD (1970). Patterns of gonadotropin secretion associated with ovulation. Federation Proceedings, 29: 1880-1887.

37. Bonnefond C, Walker AP, Stutz JA, Maywood E, Juss TS, Hebert J \& Hastings $\mathrm{MH}$ (1989). The hypothalamus and photoperiodic control of FSH secretion by melatonin in the male Syrian hamster. Journal of Endocrinology, 122: 247-254.

38. Maywood ES, Hastings MH, Ampleford E, Menake RM \& Loudon ASI (1993). Circadian and daily rhythms of melatonin in the blood and pineal gland of free-running and entrained Syrian hamsters. Journal of Endocrinology, 136: 64-73.

39. Nestler JE, Powers LP \& Matt DW (1991). A direct effect of hyperinsulinemia on serum sex hormone binding globulin in obese women with polycystic ovary syndrome. Journal of Clinical Endocrinology and Metabolism, 72: 83-89.

40. Lima FB, Matsushita DH, Hell NS, Dolnikoff MS, Okamoto MM \& Cipolla Neto $J$ (1994). The regulation of insulin action in isolated adipocytes: role of periodicity, food intake, time of day and melatonin. Brazilian Journal of Medical and Biological Research, 27: 9951000 . 